\title{
Henry Cowles, The Scientific Method: An Evolution of Thinking from Darwin to Dewey, Cambridge, MA: Harvard University Press, 2020
}

\author{
Greg Priest ${ }^{1}$
}

Accepted: 5 July 2021 / Published online: 6 August 2021

(C) Springer Nature Switzerland AG 2021

\section{Introduction}

There is no formula scientists can follow that will guarantee that their findings are valid and trustworthy. Yet we crave a simple, indubitable grounding for science. Turn on the news and listen to the sneering contempt that pundits and politicians heap on the latest findings on climate change or COVID-19. You may find yourself feeling that very craving. It should not surprise us, therefore, that the myth of a unitary and unassailable 'scientific method' has long had a powerful hold on us. Henry Cowles has written a searching, learned, and engrossing exploration of how that myth came to be created.

His narrative begins with a period that he christens (borrowing from Charles Sanders Peirce) the Age of Methods. The Age of Methods was born in the great efflorescence of methodological reflection that flowed from the pens of John Herschel, William Whewell, John Stuart Mill, and others in 1830s Britain. Although often at odds, these thinkers shared a common orientation: they attached as much importance to the method by which knowledge of the natural world is attained as to the substance of the knowledge itself. Science, they believed, justifies itself by virtue of its method.

Charles Darwin was a student of these great methodologists. And as Cowles shows, Darwin was a great methodologist in his own right. Darwin naturalized science by turning it back on itself-by subjecting scientific methods to scientific investigation. Science, he believed, is not a distinctive mode of inquiry characterized by factual precision and formal rigor, but a natural outgrowth of our evolved sensory

Greg Priest

greg@gregpriest.com

1 Department of History, Lane History Corner, Stanford University, 450 Serra Mall, Stanford, CA 94305, USA 
capacities and intellectual and imaginative faculties. Indeed, Darwin's method mirrored his subject: both nature and science evolve by a process of trial and error.

This notion-that we should study science in the same way that we study naturereverberated through the rest of the nineteenth century and into the twentieth. Alexander Bain, Herbert Spencer, and Hughlings Jackson continued to investigate scientific theorizing as an embodied activity. William James, Charles Sanders Peirce, Chauncey Wright, and the other members of the Metaphysical Club built pragmatism on this foundation. When George Romanes and Conwy Lloyd Morgan were debating animal intelligence, part of what was at stake was how animal behavior could shed light on the mental worlds of humans. And G. Stanley Hall, John Dewey, and Jane Addams extended this inquiry to the study of children, expanding the boundaries of comparative psychology from the evolving animal mind to the developing human mind.

The Age of Methods reached its apotheosis, on Cowles's account, in John Dewey. For Dewey, the scientific method is not just how we study abstruse or technical subjects; it is "how we think, full stop" (p. 260, emphasis in original). Dewey did not believe that the richness and spontaneity of human thought could be captured in a formula. But in a brief passage that would prove consequential, Dewey summarized how we think in a list of "five logically distinct steps" that take us from a question to its answer (p. 261). Dewey had meant to paint a picture of how humans in general come to believe things about the world. But publishers of scientific textbooks fetishized Dewey's five steps, transmogrifying them into a "prescriptive ritual" (p. 263), a formula that purported to guarantee true scientific knowledge. Cowles ends with an account of Abraham Flexner importing this mechanical conception of method into medicine, and of Frederick Winslow Taylor doing the same into business management, turning 'the scientific method' into an instrument of bureaucratic control.

One of the more provocative_-and to my mind beguiling — aspects of Cowles's approach is his attention to the roads not taken. His history of the scientific method ends where another author might well have chosen to begin, with the metamorphosis of Dewey's notion of science as thought into the altogether different idea of science as algorithm. This metamorphosis was far from inevitable; things so easily could have gone differently. As Cowles puts it, with a nod to Stephen J. Gould: "If you rewind from Dewey to Darwin and run the tape forward, you see all the ways this history might have been otherwise" (p. 6). In a way, then, Cowles's narrative is as much about the history that might have been as it is about the history that was.

Cowles has also chosen an original framing for his history. He begins with figures we would all recognize as canonical in the history of method. But the bulk of his book examines method through the lens of Darwin, Dewey, and the developing discipline of psychology from the mid-nineteenth to the early twentieth century. We might expect a general account of method in science to focus on, for example, physics. Cowles's choice of psychology is novel, and revealing. Method is how human minds come to know the world. Cowles's decision to study method in the context of a science of minds rather than in the context of physical bodies acted upon by external forces allows him to explore the 'looping effects' (a term he borrows from Ian Hacking) that emerge when human scientists study the operation of human minds.

Cowles also offers a fascinating suggestion regarding how Dewey's brief passage about how humans do think calcified into a prescriptive formula for how scientists 
should think. Darwin forged a naturalistic science of mind, and for fifty years Cowles's dramatis personae built upon it. Minds inhabit a world full of meanings. We interpret how beings with minds behave for insight into their purposes, and to the extent that we achieve that insight, we consider ourselves to understand those beings and their minds. In the behaviorism inaugurated by John Watson and pushed further by B. F. Skinner, this approach was turned on its head. Behavior was no longer a window onto conscious beings' minds and purposes; behavior replaced mind as the only legitimate object of a true science of psychology. Behavior could be subjected to experiment, measurement, and calculation. Watson and Skinner thus reimagined science as a realm removed from mind, with method generating truth in a process almost mechanical in its operation.

It is a compelling narrative, delivered with elegance and replete with interest. It may, however, lay more weight on Dewey's five steps of thinking than they will comfortably bear. Cowles seems to suggest that his narrative is the history of how the myth of 'the scientific method' was born and took hold. His story, he writes, is of "how Dewey's expansive account of 'how we think' was made into the narrower myth of 'the scientific method' (p. 3)." But Dewey's five steps are not the only version of the myth of the scientific method.

The goal of establishing a formula that can assure reliable knowledge of the natural world is venerable. At the dawn of the Age of Methods, Herschel argued that all science must be grounded in what Isaac Newton had called verae causae, actual causes that we can witness in operation. Mill believed that he could systematize causal reasoning into four methods. And Whewell contended that any theory supported by a consilience of unrelated inductions was thereby rendered certain. In the period after Cowles's narrative ends, the logical positivists deemed that scientific knowledge could be made certain by applying formal logic to observation statements from which theoretical commitments had been banished. And Carl Hempel claimed that we can generate valid scientific explanations by subsuming phenomena under general laws. Each of these was an attempt to define a formula that would guarantee good science, and each of these continues to resonate today when we hear of 'the scientific method.'

Cowles is right, I think, that 'the scientific method' continues to have power today not despite being a myth, but precisely because it is a myth. But neither the meaning of a myth nor its power resides in the precise words in which the myth is expressed in one particular telling. Myth is multiform, and much of its power rests in this manysidedness. Dewey's five steps of thought and their transmutation into a formula is just one version of the myth of the scientific method. When we call 'the scientific method' to mind, we hear echoes of Dewey's five steps of thought, but we also hear echoes of Herschel's demand for true causes, of the logical positivists' counsel to rid our observation statements of theoretical commitments, and of all the other versions of the myth that continue to resonate with us today.

What Cowles gives us in The Scientific Method - and it is a gift-is the history of one version of the myth of the scientific method. It is a compelling history, and he tells it well.

Publisher's Note Springer Nature remains neutral with regard to jurisdictional claims in published maps and institutional affiliations. 